\title{
Module development and its effectiveness for improving the competencies of voluntary health workers in communicating safe complementary feeding to caregivers in Indonesia
}

\author{
Dwi Nastiti Iswarawanti ${ }^{1,2,3^{*}}$, Siti Muslimatun ${ }^{4}$, Endang Basuki ${ }^{5}$ Ahmad Hadi $^{6}$ \\ ${ }^{1}$ Southeast Asian Ministers of Education Organization Regional Centre for Food and \\ Nutrition, Pusat Kajian Gizi Regional Universitas Indonesia, Jakarta; ${ }^{2}$ Department of \\ Nutrition, Faculty of Medicine, Universitas Indonesia; ${ }^{3}$ The Institute of Health Sciences \\ Kuningan, Kuningan, Indonesia; ${ }^{4}$ Indonesia International Institute for Life Sciences, \\ Jakarta; ${ }^{5}$ Department of Community Medicine, Faculty of Medicine, Universitas \\ Indonesia, Jakarta; ${ }^{6}$ Post Graduate Programme, Jakarta State University, Jakarta.
}

\begin{abstract}
Introduction: In Indonesia, most training modules for health paraprofessionals have been adapted from existing foreign modules without assessment. In addition, there have been few studies on training development for this group. We aimed to develop, using a systematic tool, implement and evaluate a training module to improve the competencies of voluntary health workers (cadres) in communicating safe complementary feeding practice to caregivers of young children in Indonesia. Methods: A mixed methods approach was used. A qualitative study employing in-depth interviews, focus group discussions, mini-workshops, documentary reviews and expert validation was used to develop the training module, following a systematic approach. The module's effectiveness for improving the health workers' competencies was evaluated using a quantitative study with a non-equivalent pre-test and post-test control group design that included 70 (intervention group) and 68 (comparison group) voluntary health workers from a peri-urban district. Changes in the workers' cognitive, affective and psychomotor competencies were tested before and after attending a 3-day training module (intervention group) or a half-day event (comparison group). Results: A 24-hour learning session module on communicating safe complementary feeding was developed and used to train voluntary health workers. After the training, a significantly higher proportion of workers in the intervention group than in the comparison group were assessed as competent in the psychomotor and composite domains (psychomotor: $67.1 \%$ vs. $20.6 \%$; composite: $74.3 \%$ vs. $36.8 \%$; $p<0.001$ ). Conclusion: This systematically developed module was effective in improving the competencies of voluntary health workers regarding communicating safe complementary feeding practice to caregivers in Indonesia.
\end{abstract}

Keywords: Competencies, complementary feeding, communication, training, voluntary health workers

\footnotetext{
*Corresponding author: Dwi Nastiti Iswarawanti MSc.

Southeast Asian Ministers of Education Organization (SEAMEO) Regional Centere for Food and Nutrition (RECFON), Pusat Kajian Gizi Regional Universitas Indonesia, Jakarta Pusat, Salemba 6,

10430, Indonesia.

Tel: +(62-21) 3913932, Fax: +(62-21) 3913933; Email: diswarawanti@gmail.com

doi: https://doi.org/10.31246/mjn-2018-0065
} 


\section{INTRODUCTION}

The high prevalence of stunting (37.2\%) among young children in Indonesia may be due to suboptimal breastfeeding and the poor quality of complementary feeding during the first six months of life (MOH Indonesia, 2013; WHO, 2009). Only $37 \%$ of children aged $6-23$ months in Indonesia are fed in accordance with the WHO's recommendations for infant and young child feeding practices $(\mathrm{MOH}$ Indonesia, 2013). The practices followed by a child's caregiver contribute to the child's nutrient intake, health status and cognitive and psychosocial development. The resources available for care may influence the capacity of the caregivers to provide appropriate care (Engle, Menon \& Hadad, 1997), including feeding. Poor hygienic practices and poor sanitation may lead to high exposure of children to unsafe food (MOH Indonesia, 2013). In addition, diarrhoea can lead to serious consequences for the growth and immune system of infants and children (Motarjemi, 2000), resulting in the child being underweight in about $61 \%$ of cases (Black, Morris \& Bryce, 2003).

Community health centres (Puskesmas) in Indonesia use the existing social network of community Integrated Health Posts (Posyandu) to help increase the coverage of areas receiving health services, among other aims, with a view to reducing mother and infant mortality rates. Routine Posyandu activity includes monthly monitoring the growth of children aged under-five and promoting good care practices. The Posyandu are run by small trained groups, referred to as cadres, who comprise non-professional female voluntary health (cadres) workers from the community. As part of their monitoring and promotional activities, cadres are expected to communicate with as well as educate and inform caregivers about nutrition (Anwar et al., 2010; Becker, 2004). However, studies have shown that most cadres in Indonesia (53\%) have never received any training. Consequently, many of the workers have poor communication skills and poor skills in growth curve interpretation (Mudjianto et al., 2003; Sukiarko, 2007). It is crucial that cadres have the basic knowledge and skills that enable them to provide appropriate advice and counselling to caregivers.

Communication has been identified as the most essential factor for effective primary healthcare teams (Sargeant, Loney \& Murphy, 2008), especially for the promotion of good nutritional practices and dietary changes (Pelto et al., 2004; Bhandari et al., 2004; Bassichetto \& Rea, 2008). Studies among health professionals, physicians and caregivers have shown that improving the communication skills of the health professionals contributes to positive behavioural changes among caregivers.

However, most training modules for local voluntary health workers have been adapted and translated from the existing modules that were prepared in developed or rich countries. They are not always effective in improving the competencies of the targeted participants. Furthermore, there has been limited investigation into the development of such training modules based on the application of systematic, scientific tools. One such approach that had previously been applied to education programmes is Kemp's model, an instructional design model that was developed by Morrison, Ross \& Kemp (2004). The model comprises nine interrelated elements (Figure 1); most of these are depicted in an oval arrangement to indicate that the design and development process is a continuous cycle that requires constant planning, design, development and assessment to ensure effective instruction. The model has been applied to various educational programmes, including those for nursing and technology (Kemp \& Rodriguez, 1992; Summerville \& Reid-Griffin, 2008), but its use for nutritional education and 


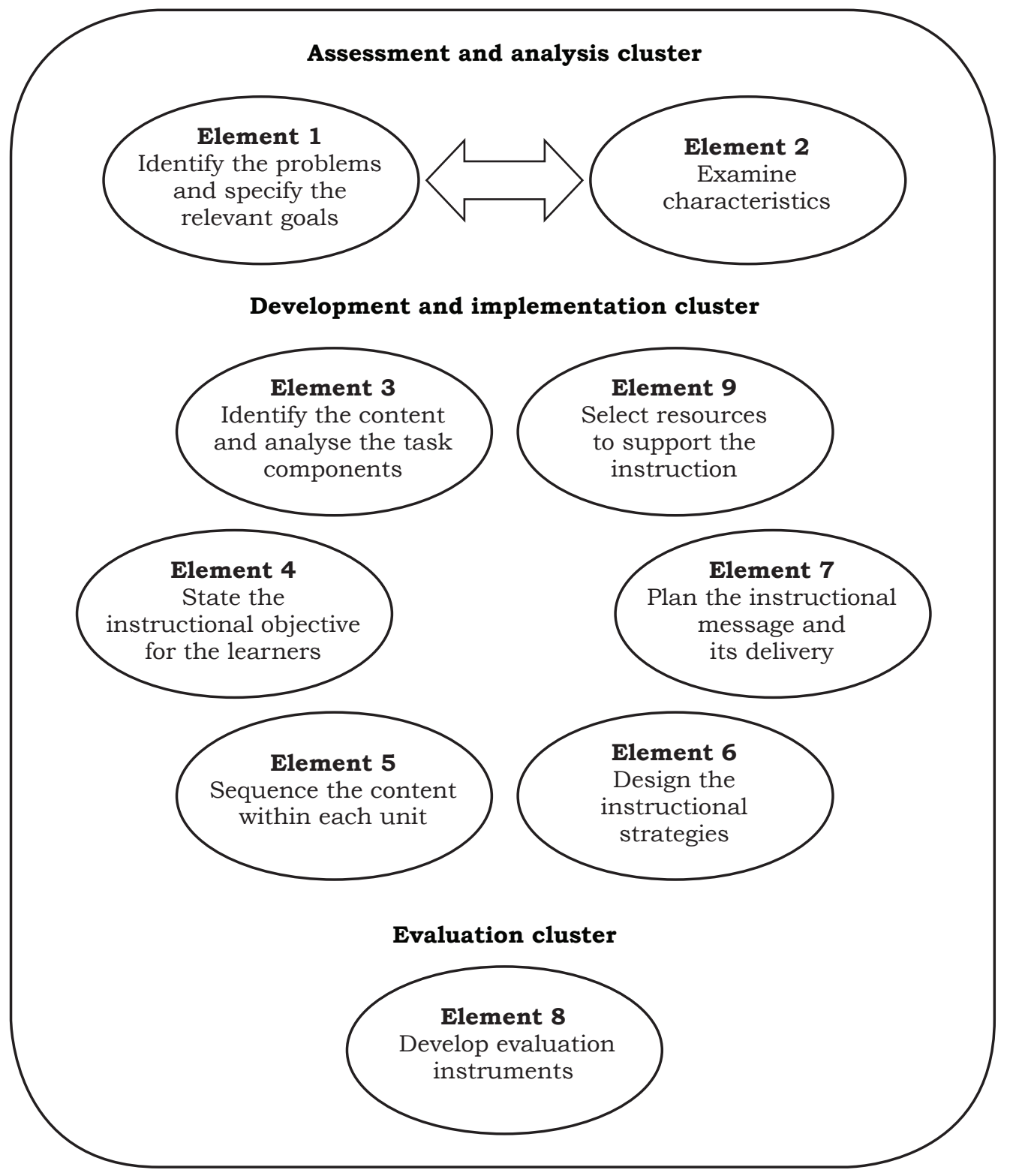

Figure 1. Elements of Kemp's model used for the development of the training module

for training paraprofessionals is limited, particularly in Indonesia.

The aim of this study was to develop, implement and evaluate a training module to improve the competencies of voluntary health workers (cadres) in communicating safe complementary feeding practice to caregivers of young children in Indonesia. Kemp's model was used to facilitate the development process.

\section{MATERIALS AND METHODS}

\section{Study design and location}

The study involved two phases: phase one was the development of the training 
module using Kemp's model and phase twowas theimplementation of the training using the developed module, which was evaluated using intervention (attended a 3-day training) and comparison groups (attended a half day event). A mixed methods approach was adopted, with a qualitative analysis of the interview material that was obtained during phase one and a quantitative assessment of the results of the phase two evaluation. The study took place in Bekasi District, Indonesia, which is about $20 \mathrm{~km}$ from Jakarta. This study was conducted with approval from the Human Ethics Committee of the Faculty of Medicine of Universitas Indonesia. All participants were informed about the purpose of the study and gave their written consent for voluntary participation.

\section{Phase one: Training module development}

According to Kemp's model, each element of the training programme development process (Figure 1) should be considered independently but iteratively. The elements required different methods of gathering information, such as literature reviews, discussions with three relevant experts, focus group discussions (FGDs) with cadres (four times), caregivers (twice), mini workshop with health office staff (once), and in-depth interviews (IDIs) with district health staff (11 times) (Table1). The FGDs or IDIs were discontinued when the researcher did not obtain anymore new issues. The respondents representing government workers were staff of the Bekasi Regional Health Office and its associated community health centres. The respondents representing the community were cadre workers and caregivers of children aged 0-23 months in the North Bekasi sub-district. The study also recruited several experts from various backgrounds, including nutritionists, communication specialists, educational technologists and a media designer who designed the communication media or learning materials.

The training module involved various instruments, including slides, videos, brochures, posters, booklets and questionnaires. These were pretested on suitable respondents, such as caregivers, cadre workers and health staff, from different areas with similar community characteristics. The local health polytechnic, health centres, health research and development centre and the Nutrition Directorate of the Ministry of Health $(\mathrm{MOH})$ were approached to identify potential trainers, who were then recruited on the basis of their curriculum vitae and an interview. Eleven potential trainers were invited to participate in the training of the trainers (ToT) programme and underwent further assessments.

The final draft of the training module with all the training instruments was sent for validation to three external reviewers: a senior nutritionist, an educational technologist and a certified national trainer. The reviewers validated the module according to a list of criteria that was developed by the health human resource section of the $\mathrm{MOH}$, which included the sequence and appropriateness of the chosen topics, conformity between the topics and objectives, the clarity and accuracy of the information, the consistency of terminology, time allotment, the appropriateness of the chosen method and the appropriateness of the chosen instruments. The training module was revised according to the reviewers' comments. It was then used for the ToT, which was delivered by four facilitators and overseen by one external evaluator. As well as allowing the trainers to practise and gain mastery of the training content, this activity served as a formative evaluation of the module. The ToT programme lasted five days, with all 11 potential trainers taking part. The external evaluator assessed the whole 
training process. The potential trainers attained a score $>70 \%$ for their training mastery and were considered qualified as trainers.

\section{Quality control}

Suitably experienced personnel were recruited and trained to act as FGD moderators, in-depth interviewers, observers and note-takers and technicians for video- or audiorecording. The experts invited to assist in training module development were required to have at least ten years of experience in their field. These experts were nutritionists, communication specialists, education technologists and a certified national trainer. The training facilitators were national master trainers in nutrition and health with at least five years' experience.

Several manuals were developed to ensure that the data and information collection procedures were standardised. The instruments for the FGDs and IDIs were pretested prior to use. Logbooks and photos were prepared to record progress with each step of the study. In addition, pictures and videos were taken and filed (Smith \& Ragan, 2005).

\section{Data analysis}

Audiotapes of all of the interviews, including the FGDs, IDIs and unstructured interviews, were transcribed verbatim. The transcripts were read repeatedly by a single researcher and then analysed systematically according to content analysis procedures by coding responses and identifying common themes. A matrix was constructed of the themes and notable quotations for each interview question.

\section{Phase two: Implementation of training}

The second phase of the study was carried out in two selected sub-districts that were located about $30 \mathrm{~km}$ from each other: Bekasi Timur (for the intervention group) and Pondok Gede (for the comparison group). These subdistricts were comparable in terms of the prevalence of underweight children, number of cadres and coverage of Posyandu activity (Linn \& Gronlund, 1995).

\section{Sample size and enrolment}

The implementation was evaluated using a pre-post design with a comparison group (Lemenshow et al., 1993). The required sample size was calculated to be 70 cadre workers for each group to achieve a confidence level of $95 \%$, power of $80 \%$, anticipated proportions of cadre workers competent in communicating safe complementary feeding of $20 \%$ before the intervention and 60\% after the intervention (Mudjianto et al., 2003), a design effect of 1.5 and an expected $10 \%$ loss to follow-up. The inclusion criteria for cadre workers were age 25-60 years, senior high school graduates and willingness to be followed-up for endline assessment.

Seventy cadres were randomly selected and enrolled, out of the 147 eligible cadre from the 35 Posyandu in the intervention area. Seventy-one cadres were randomly selected and enrolled out of the 147 eligible workers from the 36 Posyandu in the comparison area. However, three of the latter were unable to attend the seminar because of illness or family matters, leaving a total of 68 participants in the comparison group.

\section{Training}

The training module was delivered in two training formats, a 3-day training course for the intervention group and a half-day seminar for the comparison group. The 3-day courses were presented in three batches, each with 22-25 participants. Each session was facilitated by one instructor and one or two assistants; in total, nine trained instructors delivered the training. The class environment was carefully prepared to ensure a conducive 
learning atmosphere. The half-day seminar for the comparison group was delivered once by four trained instructors, with all 68 participants in attendance. It was held in a multi-purpose room of the village office, according to the existing practice of the study area.

\section{Competency assessment}

The cognitive and affective competencies of the participants were assessed 2-4 weeks before they attended the training or seminar (baseline) and again after it (endline), using pretested, structured questionnaires administered by trained evaluators. Communication sessions with caregivers were also arranged to assess each participant's psychomotor competency. It was video-recorded, and the recordings were viewed independently by two trained evaluators, who assessed the participant's psychomotor competency according to a pretested structured checklist. The evaluators received prior training from the communication specialist, and the video recordings were coded using a double-blind randomised method in which the researcher and the two evaluators were unaware of whether the recordings were acquired during the endline assessments, for both the intervention and comparison group.

\section{Quality control}

The collected competency assessment data were peer-reviewed by trained evaluators and regularly checked by field coordinators for correctness of coding, completeness, clarity and consistency of the information. The field coordinator then re-interviewed $10 \%$ of the entire sample. The assignments of the evaluators were rotated according to the type of group and time (baseline/ endline) of the assessment (Smith \& Ragan, 2005).

To ensure content validity, the content of the structured questionnaires and observation checklists was carefully prepared, and verified by experts. Face validity was checked by pre-testing the instruments to ensure their clarity and acceptability by both the evaluators and the respondents. Cronbach's alpha coefficients for the cognitive and affective components were 0.791 and 0.900, respectively. A logbook was used to record the conduct of the try-out training. Preand post-tests were employed to assess learning achievement during training for cadres or trainers.

\section{Data analysis}

In the cognitive competencies instrument which comprised 27 items, each correct answer was scored 1 point. In the affective competencies instrument which comprised 14 items, each statement was answered as 'strongly agree' (4 points), 'agree' (3 points), 'neither agree nor disagree' (2 points), 'disagree' (1 point) and 'strongly disagree' ( 0 points). In the psychomotor instrument, each of the ten items was scored as 0 points for no performance or an incorrect performance, 1 for an irregular performance and 2 for a correct and complete performance, with the results from the two evaluators added together. Each type of competency was assessed as the participant's total score as a percentage of the total possible score. The participant's total scores for each type of competency were combined into a composite score by applying weightings of $30 \%$ each for the cognitive and affective competencies and $40 \%$ for the psychomotor competencies. Participants whose composite scores exceeded a cut-off point of $70 \%$ were considered to have mastered the competencies (Azhar, 2010).

Data from the questionnaires were analysed using SPSS for Windows version 16.0 after randomly rechecking $10 \%$ of the entered data for errors against the completed questionnaires. The data distributions were checked for normality using the KolmogorovSmirnov test. Differences between and within the intervention and comparison 
groups in the scores for each competency were tested using independent $t$-tests and McNemar's test respectively with a significance level of $5 \%$. Differences between the two groups in the proportion of participants considered competent in each competency category were tested using Fisher's exact test with a significance level of $5 \%$. Further analysis using multivariate logistic regression was performed to assess the association between each type of competency and other potential personal factors, including the participants' ages, experience, education level, household monthly income, other nutrition training received and competency at baseline.

\section{RESULTS}

\section{Phase one: Module development}

Initially, while developing the training module, the researcher used the nine elements of Kemp's instructional model (Figure 1) in sequence. However, to ensure content conformity and completeness, almost all of the elements were revisited two or three times. Table 1 summarises the results related to each element of Kemp's model.

The FGDs revealed that the young children in the study area were frequently exposed to chemical hazards from streetvendor foods (which relates to Element 1 of Kemp's model, 'Identify the problems and specify the relevant goals'). Items on the nature of chemical contamination and the impact of chemical hazards on children's health were therefore added to the training materials (Element 4, 'State the instructional objective for the learners'). In addition, further in-depth interviews with local health staff were conducted to redefine the topic priorities (Element 1).

The initial draft module contained material for a 5-day course. While assessing this draft (Element 4), the researcher reviewed existing problems (Element 1) and characteristics of the cadres (Element 2, 'Examine characteristics'). Because of the limited time available to the cadre workers and trainers, the researcher decided to reshape the training into a 3-day course, while taking into consideration the required competencies (Element 3, 'Identify the content and analyse the task components').

The results of the interviews and discussions with health staff and cadre workers showed that they were aware of the problems that exist regarding nutrition and of the underlying factors that can lead to under-nutrition among young children in their areas (Element 1). Given the characteristics, preferences and challenges of the cadre workers, such as their work overload, management responsibilities, their age (the majority were aged 40-50 years) and their preference for listening to the material rather than reading it, it was decided that the format of the training should be interactive and use adult learning methods (Elements 2 and 3). The training included learning objectives in the cognitive, affective and psychomotor domains. These were formulated to meet the following criteria: (a) the cadre workers would understand the basic concept, principles and facts regarding safe complementary feeding and the communication of this; (b) they would be able to analyse existing feeding practices and to compare them with other relevant practices or evaluate them using guidelines provided in the training; (c) they would be aware about the problems in their community and willing to respond to these by providing information to caregivers and (d) they would be able to apply the theory of safe complementary feeding and to implement the communication steps correctly.

Hence, the instructional objectives for the cadre workers (Element 4) were that they should be able to communicate with caregivers and advise them consistently on implementing correct and safe complementary feeding practices. The 'What are?' content of the 


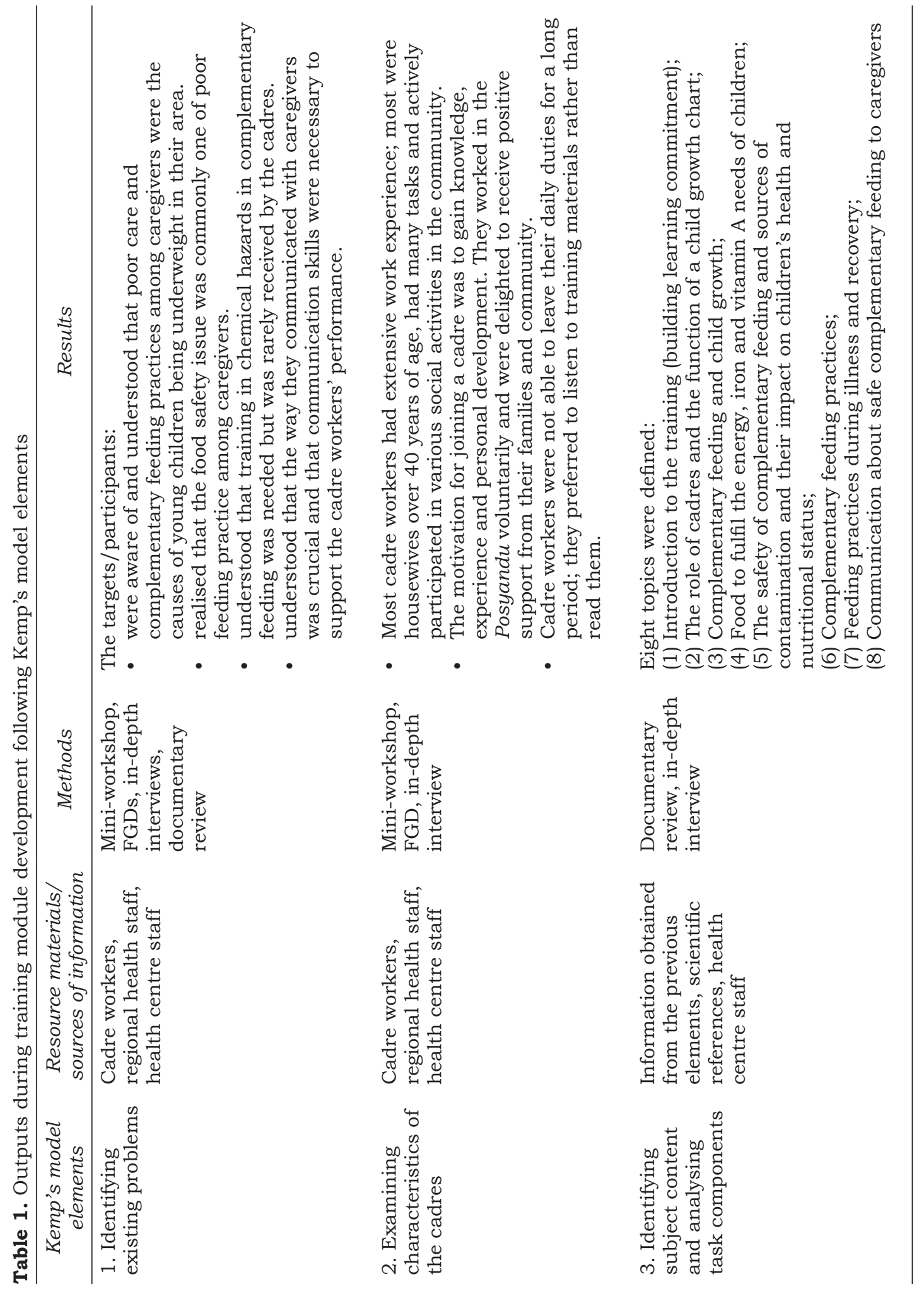




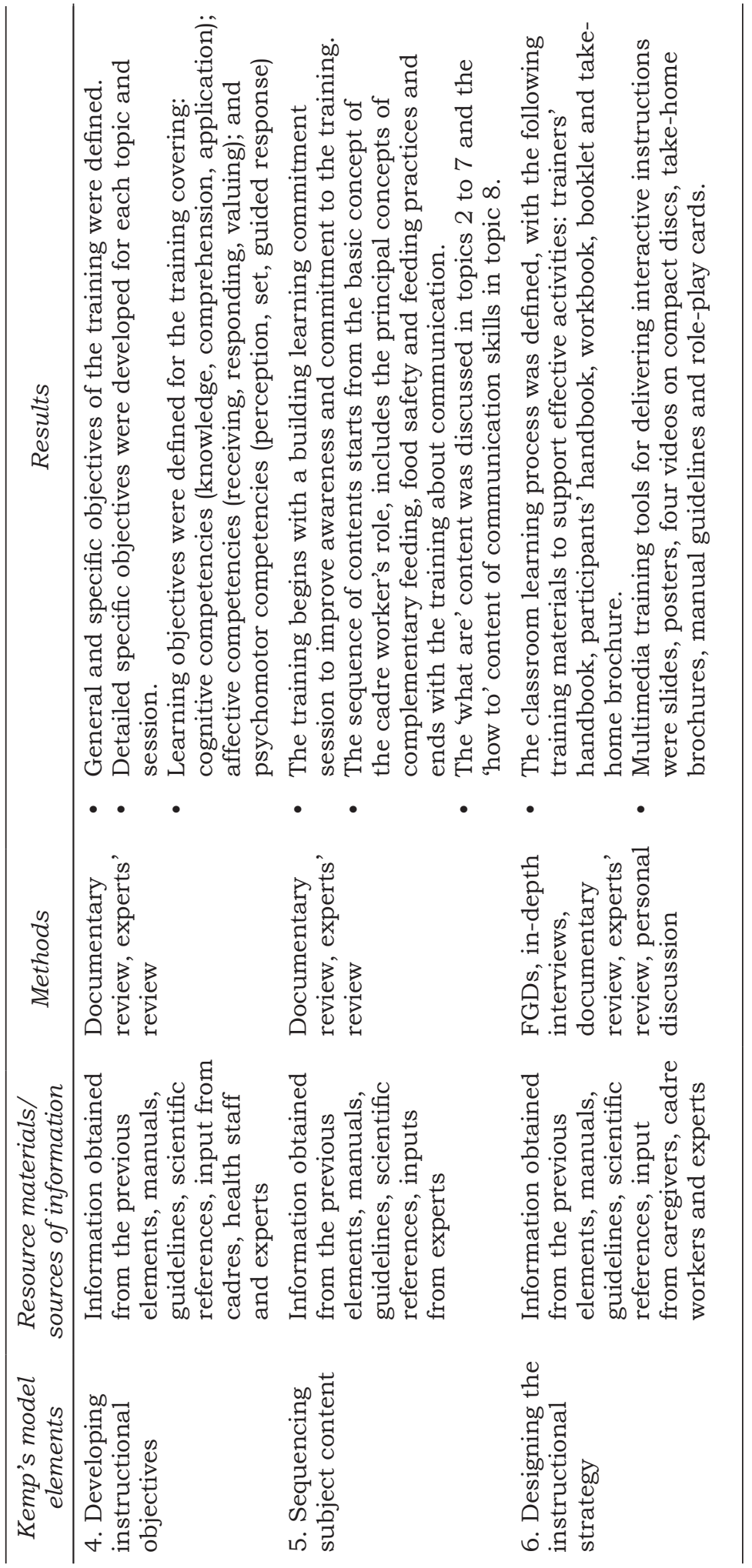




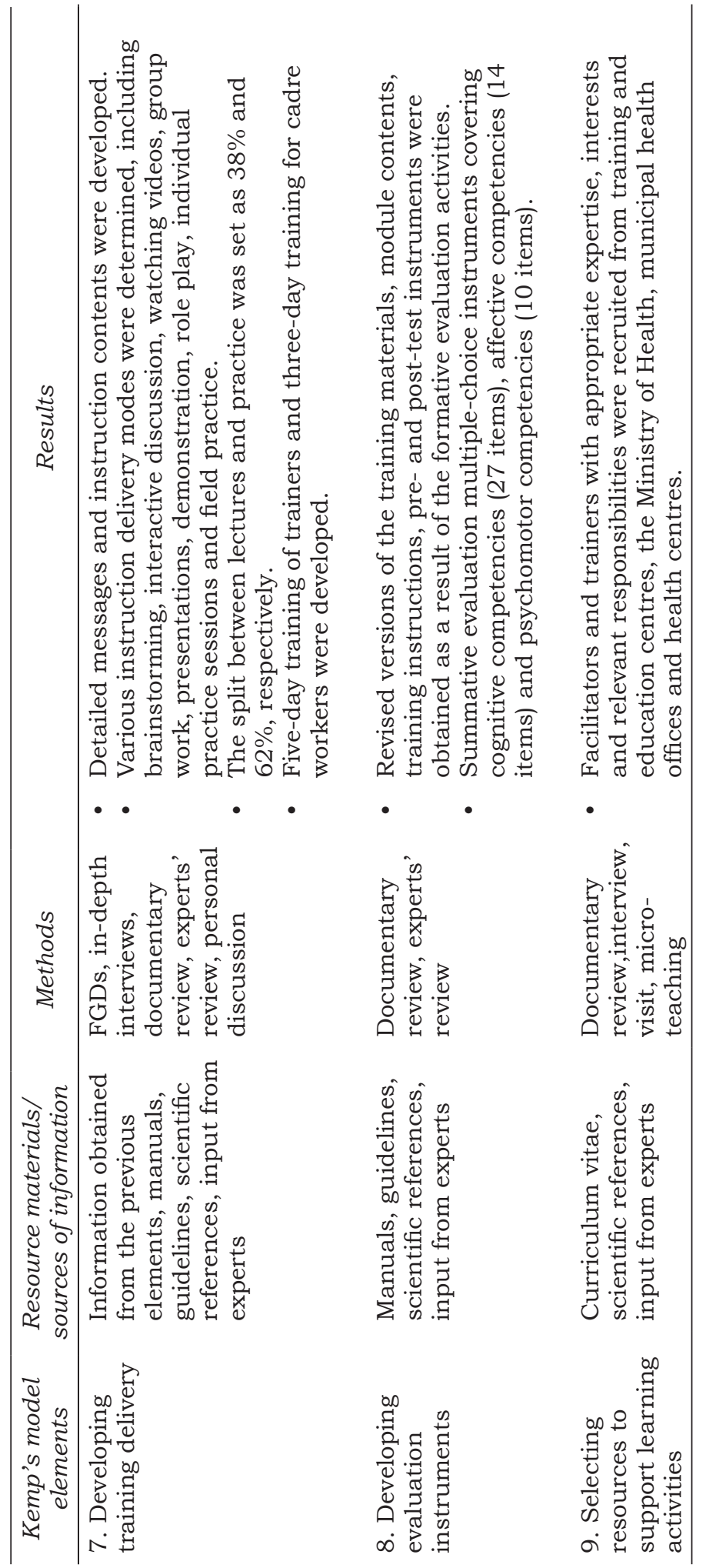


training module was discussed in topics $2-7$, followed by the 'How to' content about communication skills in topic 8 (Element 5, 'Sequence the content within each unit'). The training was intended to be a classroom learning process, so it was decided that training materials should be developed in addition to the training instruments to support effective learning activities using adultlearning principles (Element 6, 'Design the instructional strategies'). The training used various delivery methods, including lectures, brainstorming, roleplay, presentations, demonstrations, problem-solving exercises, watching videos and practice (Element 7 , 'Plan the instructional message and its delivery'). Summative evaluation was performed to assess the achievement of competencies and formative evaluation to maintain the reliability of the training development process (Element 8, 'Develop evaluation instruments'). Eleven regional health office and community health centre staff with responsibilities in nutrition and health promotion programmes were selected as the trainers, and four national master trainers in communication and/or nutrition were recruited as the facilitators of ToT (Element 9, 'Select resources to support the instruction').
An expert panel validated the accuracy of the following aspects of the training module: the sequence and appropriateness of the chosen topics; conformity of the topics to the objectives; the clarity and accuracy of the information; the consistency of terminology; the time allotment to each activities within the module; the appropriateness of the chosen methods and the appropriateness of the chosen instruments. An external educational expert performed the training validation during the ToT process by, evaluating the implementation of the use of structured and unstructured evaluation guidelines. The purpose of the ToT was to produce trained instructors with the optimum level of knowledge and mastery to deliver the training module in a consistent way and to verify the consistency between the learning process and the developed module.

\section{Phase two: Training implementation}

In general, the characteristics of the participants were similar in the two groups (Table 2). Most of the participants were housewives with a household monthly expenditure above the minimum wage rate. The median times spent as the cadres workers by

Table 2. Characteristics of the participants

\begin{tabular}{|c|c|c|c|}
\hline Variables & $\begin{array}{l}\text { Intervention } \\
\text { group }(N=70)\end{array}$ & $\begin{array}{l}\text { Comparison group } \\
(N=68)\end{array}$ & p-value \\
\hline Age (year), Mean $\pm S D$ & $47.7 \pm 5.8$ & $42.9 \pm 8.0$ & $0.006^{*}$ \\
\hline \multicolumn{4}{|l|}{ Education (\%) } \\
\hline 10-12 years (high school) & 88.6 & 77.9 & \multirow[t]{2}{*}{0.074} \\
\hline $\begin{array}{l}\geq 13-15 \text { years (diploma and } \\
\text { university) }\end{array}$ & 11.4 & 22.1 & \\
\hline \multicolumn{4}{|l|}{ Time spent as cadres (years) } \\
\hline $\begin{array}{l}\text { Range } \\
\text { Median }\end{array}$ & $\begin{array}{l}1-24 \\
8.0\end{array}$ & $\begin{array}{l}1-23 \\
5.0\end{array}$ & 0.321 \\
\hline $\begin{array}{l}\text { Previous training in nutrition (\%) } \\
\text { Monthly expenditure }\end{array}$ & 38.6 & 50.0 & 0.230 \\
\hline $\begin{array}{l}>\mathrm{IDR}^{\dagger} 1,275,000(\%) \\
\text { Occupation }(\%)\end{array}$ & 90.0 & 95.6 & 0.326 \\
\hline Housewife & 88.6 & 82.4 & 0.282 \\
\hline Others (vendor, entrepreneur) & 11.4 & 17.6 & \\
\hline
\end{tabular}

${ }^{\dagger} 1 \mathrm{US} \$=9600 \mathrm{IDR}$

*Significant at $p<0.05$ using independent samples $t$-test 
Table 3. Proportion of the participants in the intervention and comparison groups assessed as competent for each competency type and overall

\begin{tabular}{|c|c|c|c|}
\hline Competencies & $\begin{array}{l}\text { Intervention group, } N=70 \\
\text { (n) } \%\end{array}$ & $\begin{array}{c}\text { Comparison group, } N=68 \\
\text { (n) } \%\end{array}$ & $\begin{array}{c}\text { p-value } \\
\text { between } \\
\text { groups }\end{array}$ \\
\hline \multicolumn{4}{|l|}{ A. Cognitive } \\
\hline Baseline & (29) 41.4 & (27) 38.2 & 0.417 \\
\hline Endline & (53) 75.7 & (49) 70.6 & 0.313 \\
\hline$p$-value within group ${ }^{\dagger}$ & $<0.001^{* *}$ & $<0.001^{* *}$ & \\
\hline \multicolumn{4}{|l|}{ B. Affective } \\
\hline Baseline & (34) 48.6 & (28) 39.7 & 0.190 \\
\hline Endline & (43) 61.4 & (30) 42.6 & $0.021^{*}$ \\
\hline$p$-value within group ${ }^{\dagger}$ & $<0.001^{* *}$ & $<0.001^{* *}$ & \\
\hline \multicolumn{4}{|l|}{ C. Psychomotor ${ }^{\dagger}$} \\
\hline Baseline & (0) 0 & (0) 0 & - \\
\hline Endline & (47) 67.1 & (14) 20.6 & $<0.001^{* *}$ \\
\hline$p$-value within group & - & - & \\
\hline \multicolumn{4}{|l|}{$\begin{array}{l}\text { D. Composite } \\
(30 \% A+30 \% B+40 \% C)\end{array}$} \\
\hline Baseline & (8) 11.4 & (4) 5.9 & 0.197 \\
\hline Endline & (52) 74.3 & (26) 36.8 & $<0.001^{* *}$ \\
\hline$p$-value within group ${ }^{\dagger}$ & $<0.001^{* *}$ & $<0.001^{* *}$ & \\
\hline
\end{tabular}

${ }^{\dagger} p$-value within the groups using McNemar's test, at a significance level of $5 \%$

${ }^{\ddagger} p$-value between the groups using Fisher's exact test, at a significance level of $5 \%$

"significant, $p<0.05$

**significant, $p<0.001$

the participants in the intervention and comparison groups were eight and five years, respectively. The participants in the intervention group were significantly older than those in the comparison group.

Table 3 summarises the proportions of the participants in the intervention and comparison groups who were assessed as competent for each competency type and overall. In both groups, the proportion of participants assessed as competent in the cognitive competencies at endline increased significantly compared to baseline, but with no significant difference between the groups. For the affective competencies, a similar proportion of participants in both groups were assessed as competent at baseline, but a significantly higher proportion of the intervention group than the comparison group were assessed as competent at endline $(p=0.021)$. The psychomotor competencies were not assessed at baseline. At endline, the proportion of participants who were assessed as competent in the psychomotor competencies was significantly higher in the intervention group than in the comparison group $(67.1 \%$ vs. $20.6 \%$; $p<0.001)$. The proportion of participants with overall competence, as assessed by the composite score, increased in both groups, but the intervention group had a significantly higher proportion than the comparison group $(74.3 \%$ vs. $36.8 \%$; $p<0001)$.

Table 4 summarises the results of the multivariate analysis. The intervention was the only variable that significantly influenced the changes in psychomotor and composite competencies, with odds ratios of 9.13 (95\% CI: 3.20-26.02) for the 


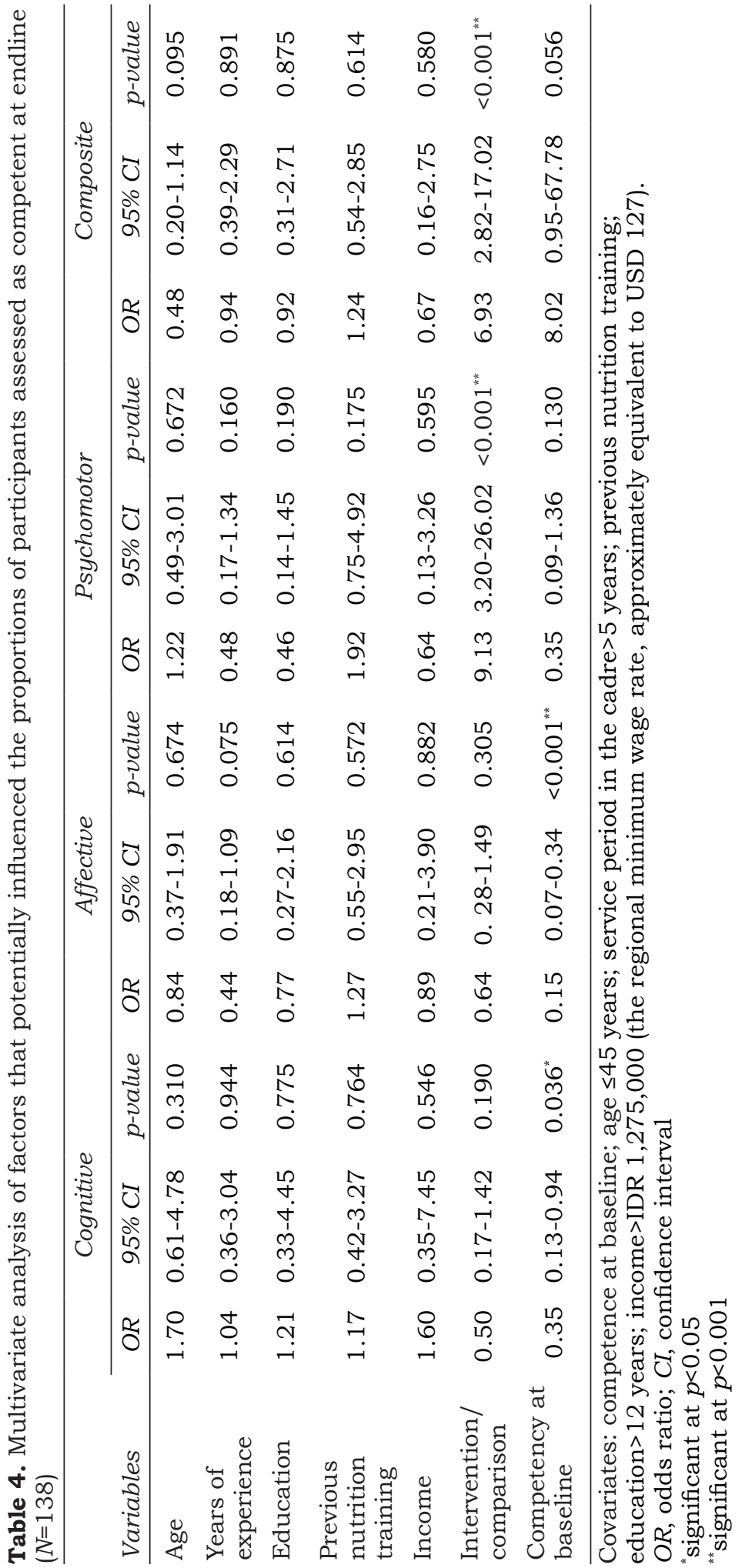


psychomotor competencies $(p<0.001)$ and 6.93 (95\% CI: 2.82-17.02) for being assessed as competent according to the composite score $(p<0.001)$.

\section{DISCUSSION}

This study showed that the development of a training module requires considerable and thorough work with solid teamwork (Smith \& Ragan 2005). Designing a new instructional module is not simple. While developing the module in this study, each element was carefully reviewed in order to obtain relevant and consistent instruction with logical flow. The development and revision of the elements of the Kemp model was iterative because all were interrelated and described a continuous process. The team members including the media designers and printers who were involved in producing videos, booklets, posters, brochures and other instruments. The recruitment of the facilitators and trainers was undertaken with care to ensure that they were effective and committed. Tests and retests of individual targets or groups were performed to assess the accuracy, clarity and consistency of the materials. Expert reviews were conducted to assess the congruence of the instruction materials with the identified learning objectives. The development of this training module required adequate time, a good recordkeeping system and a team with various experts. The instructional module designer should also consider the cost of the production of training materials and tools (Smith \& Ragan, 2005).

The content and face validities of the instruments were established through intensive discussions with related experts and re-testing with different target groups. Valid and reliable instruments are crucial to ensure the reproducibility of a study as well as to judge the effectiveness of the training (Smith \& Ragan, 2005; Linn \& Gronlund, 1995; Brown, 2007). The Cronbach's alpha coefficients of the cognitive competencies, affective competencies and caregiver questionnaires were high (0.791, 0.900 and 0.866 , respectively), showing good reliability of these instruments (Portney \& Watkins, 2009). The self-administered questionnaires for cognitive and affective competencies were tested on cadre workers to gain insight into the questions and to reduce the bias of the evaluators. The respective evaluators closely supervised the process.

A previous study on communication training for midwives demonstrated that self-assessment was a reliable measure for evaluating their skills (Basuki, 2003). In the present study, the assessment results confirmed that the instruments had high reliability in terms of measuring the motivations and self-efficacy of the cadres. However, indirect observation by a trained evaluator sometime after the implementation of training can provide a more reliable method for assessing retention of the learning (Linn \& Gronlund, 1995).

\section{Cognitive competencies}

The statistical analysis showed that no personal factors (other than the initial level of competence) influenced the cognitive competencies of the participants. Most of the participants had extensive experience as cadres and had received some prior training in nutrition, as a result of which the baseline knowledge scores of the participants were quite high. Even though the cognitive competencies in both groups improved significantly, the final scores and number of participants assessed as competent were slightly higher in the intervention group than in the comparison group that received only a seminar. The change in the competencies scores among the training group was considered high: 18.5 and 19.5 points, respectively, during the training (pre-post-test) and two to four 
weeks after the intervention period (baseline-endline)(data not shown).

The improvement in the recall and comprehension levels of the participants after attending the seminar was not significantly different from those of their counterparts in the comparison group. This shows that information dissemination via seminars is a good way to enhance the lowest level of cognitive competency. It also suggests that the slides, video, booklets and posters that were used in the seminar were clear, consistent and efficient in terms of enabling knowledge acquisition, particularly at the lowest levels, such as for knowledge/recall and comprehension.

The seven learning issues in which the participants had the lowest score at the beginning of the study but the highest achievement score after the training were as follows: (1) the correct combination of age, type and frequency of complementary feeding; (2) the portion sizes for complementary feeding; (3) the benefit for children of food with a thick consistency; (4) the optimal temperature range for microbial pathogen growth; (5) the symptoms of children with foodborne illnesses; (6) the definition and examples of open-ended questions and (7) the correct body language during communication. Coverage of these issues should be mandatory in any training curricula.

\section{Affective competencies}

The proportion of participants who were assessed as competent in the affective competencies was significantly higher among those who received the training compared with their counterparts, perhaps because the training allowed them to share their experiences and learn how their colleagues solved problems (Coon, 2006; Bourgeois et al., 2004). They shared their experience regarding complementary feeding, feeding practices, the risk of unsafe food and communication issues, and they learned how to deal with difficult situations, raising their awareness of problems that exist in their communities. The case studies on child growth monitoring, complementary feeding, critical hygiene practices and communication practice during training influenced the motivation and risk perception of the participants. Frequent and intensive exposure through multimedia might have further increased the confidence and motivation of the participants (Gregory \& Chapman, 2007; Coon, 2006).

The enjoyable training environment, resourceful trainers and well-organised training and materials resulted in the participants responding positively to the learning process. They also met their colleagues, which motivated them to learn and share with each other (Linn \& Gronlund, 1995; Coon, 2006; Gregory \& Chapman, 2007). By the end of the training, they acknowledged that all the topics were useful and easy to understand. They were grateful for the knowledge and skills they had been given and indicated their desire to share the information with other colleagues as well as implement it within their posyandu. It was clear that implementation of this training module produced a conducive learning environment, as well as effective methods and instruments, which influenced the effectiveness of the training (Smith \& Ragan, 2005). However, there was no opportunity for the comparison group participants who attended the seminar to share and discuss the topics that were presented during the sessions. Most of the activities covered in the seminar were lectures, with limited discussion. As a result, the participants had no opportunity to internalise the material properly and this was confirmed by the lack of significant improvement in their affective competencies. The comparison group participants were advised to learn from the materials that were provided 
before implementation. However, the intensity of their implementation would depend on their readiness to do so.

\section{Psychomotor competencies}

The psychomotor competencies of the participants in communicating safe complementary feeding improved with training. The communication practice sessions during the class gave them opportunities to apply their skills. Practice in the field by visiting the homes of caregivers gave the participants experience in a real-life setting. The participants were used to dealing with a wide range of problems related to complementary feeding in the community (Coon, 2006). Repeated watching of a video increased their opportunity to learn the appropriate gestures, capture the appropriate expressions and improve their understanding of the principles of non-verbal communication (Gregory \& Chapman, 2007).

\section{Overall competence in communicating about safe complementary feeding}

Any practice that an individual performs consistently and repeatedly becomes closely related to their character. Character comprises three interrelated parts, namely moral knowing, moral feeling and moral behaviour. These parts do not function independently but interrelate and influence each other in a variety of ways. The cognitive and affective competencies of the participants were reflected in their psychomotor competencies as well as in their composite scores. The psychomotor and composite scores of the participants in the intervention group significantly improved after the training. In addition, the increase in the cognitive competencies scores of the intervention participants was quite high, at 14.2, although not significantly different from that in the comparison group. The overall competence of the participants in communicating information about safe complementary feeding was indicated by the composite scores that were based on the cognitive, affective and psychomotor competency scores. Change in the competencies of the participants in the cognitive domain will influence their attitudes and so would be reflected in their behaviour (Lickona, 1992).

To turn competencies in communication into a behaviour or habit requires follow-up training to refresh them. A study using pre- and post- surveys on communication skills training for nurses of elderly people with dementia showed that their skills could be maintained for more than three months, with a high level of performance maintained for up to 22 weeks after the training (Bourgeois et al., 2004). However, communication skills can decrease over a 6-month period, with a loss of the improvement in the skills after 12 months (Ripich, Ziol \& Lee, 1998).

\section{CONCLUSION}

This study used systematic and scientific methods to develop a training module for voluntary health workers to improve their communication of safe complementary feeding to caregivers of young children. A detailed evaluation demonstrated that the developed training module was effective in improving the competencies of those who attended the training.

\section{Acknowledgment}

The authors thank the cadres, caregivers and the staff of Bekasi Municipality Health Office and their Puskesmas.

\section{Authors' contributions}

IDN, principal investigator, conceptualised and designed the study, conducted data collection, analysis and interpretation, and prepared the draft of the manuscript; MS, conceptualised and designed the study, read and reviewed the manuscript; $\mathrm{BE}$; conceptualised and designed the study, read and reviewed the manuscript; HA, conceptualised and designed the study.

\section{Conflict of interest}

The authors declare that they have no conflicts of interest. The study was supported by Nestle Foundation, which had no role in the design, analysis or writing of this article. 


\section{References}

Anwar F, Khomsan A, Sukandar D, Riyadi H \& Mudjajanto ES (2010). High participation in the posyandunutrition program improved children nutritional status. Nut Res Prac 4(3):208-214.

Azhar (2010). Pengembangan instrumen penilaian kompetensi guru mata pelajaran fisika SMA/ $M A$. Dissertation. Unpublished. Postgraduate program of UniversitasNegri Jakarta, Jakarta.

Bassichetto KC \& Rea MF (2008). Infant and young child feeding counselling: an intervention study. J Pediatr (Rio J) 84(1):75-82.

Basuki ESM (2003). Pengaruh metode penilaian diri terhadap keterampilan bidan praktek swasta dalam melakukan konseling keluarga berencana. Dissertation. Dissertation. Postgraduate program of the Public Health Faculty, Universitas Indonesia.

Becker J (2004). Individual empowerment: how community health workers operationalize selfdetermination, self-deficiency, and decisionmaking abilities of low-income mothers. J Com Psy 32(3):327-342.

Bhandari N, Mazunder S, Bahl R, Martines J, Black RE, Bahn MK \& Infants Feeding Study Group (2004). An educational intervention to promote appropriate complementary feeding practices and physical growth in infants and young children in Rural Haryana, India. $J$ Nutr134(9):2342-2348.

Black RE, Morris SS \& Bryce J (2003). Where and why are 10 million children dying every year? (2003). Lancet 361(9376):2226-2234.

Bourgeois MS, Dijkstra K, Burgio L \& Allen RS (2004). Communication skills training for nursing aides of residents with dementia: the impact of measuring performance. Clin Gerontol 27(1/2):119-138.

Brown HD (2007). Teaching by principles: an interactive approach to language pedagogy. $3^{\text {rd }}$ ed. Pearson Education Inc., New York.

Coon D (2006). Psychology: A modular approach to mind and behavior. $10^{\text {th }}$ edn. Thomson Learning, Belmont.

Engle PL, Menon P \& Hadad L (1997). Care and nutrition: concepts and measurement. International Food Policy and Research Institute. Washington DC.

Gregory GH \& Chapman C (2007). Differentiated instructional strategies: one size doesn't fit all. $3^{\text {rd }}$ edn. Sage Publication. Corwin, CA, USA.

Kemp JE \& Rodriguez L (1992). The Basics of instructional design. $J$ Contin Educ Nurs 23(6):282-284.

Lemenshow S, Hosmer DW, Klar J \& Lwanga S (1993). Adequacy of sample size in health studies. John Willey \& Sons, New York.
Lickona T (1992). Educating for character: how our schools can teach respect and responsibility. $1^{\text {st }}$ Ed. Bantam Books, New York.

Linn RL \& Gronlund NE (1995). Measurement and Assessment in Teaching. $9^{\text {th }} \mathrm{Ed}$. Merril, an imprint of Prentice-Hall Inc. New Jersey.

MOH Indonesia (2013). Basic health research (Riset Kesehatan Dasar). Health Research and Development Center.

Morrison GR, Ross SM \& Kemp JE (2004). Designing effective instruction. $4^{\text {th }} \mathrm{Ed}$. John Wiley \& Sons Inc., New York.

Motarjemi Y (2000). Research priorities on safety of complementary feeding. Pediatrics 106(5):1304-1305.

Mudjianto TT, Hidayat TS, Hermina, Luciasari E, Afriansyah N \& Fuada N (2003). Faktor-faktor positif untuk meningkatkan potensi kader posyandu dalam upaya mencapai keluarga sadar gizi. Penelitian Gizi dan Makanan 26(2):27-34.

Pelto GH, Santos I, Goncalves H, Victoria C, Martines J \& Habict JP (2004). Nutrition counseling training changes physician behavior and improves caregiver knowledge acquisition. J Nutr 134(2):357-364.

Portney LG \& Watkins MP (2009). Foundations of clinical research applications to practices. $3^{\text {rd }}$ Ed. Prentice Hall Health, New Jersey.

Ripich DN, Ziol E \& Lee MM (1998). Longitudinal effect of communication training on caregivers of persons with Alzheimer's disease. Clin Gerontol 19(2):37-55.

Sargeant J, Loney E \& Murphy G (2008). Effective interprofessional teams: "Contact is not enough" to build a team. $J$ ContinEduc Health Prof 28(4):228-234.

Smith PL \& Ragan TJ (2005). Instructional Design. 3rd Ed. John Wiley \& Sons Inc., New Jersey.

Sukiarko E (2007). Pengaruh pelatihan dengan metode belajar berdasarkan masalah terhadap pengetahuan dan keterampilan kader gizi dalam kegiatan posyandu. Unpublished. Thesis. Post Graduate Program, Universitas Diponegoro, Semarang Indonesia.

Summerville J \& Reid-Griffin A (2008). Technology integration and instructional design. Tech Trends 52(5):45-51.

WHO (2009). WHO child growth standards: Growth velocity based on weight, length and head circumference. method and development. Department of Nutrition for Health and Development, World Health Organization, Geneva. 